\title{
PENERAPAN ALGORITMA DECISION TREE C4.5 BERBASIS PARTICLE SWARM OPTIMIZATION (PSO) UNTUK PREDIKSI TINGKAT KEPUASAN PELAYANAN OBAT
}

\author{
Erfan Karyadiputra ${ }^{1)}$, Agus Setiawan ${ }^{2)}$ Nadiya Hijriana $^{3)}$ \\ ${ }^{1}$ Fakultas Teknologi Informasi, Universitas Islam Kalimantan Muhammad Arsyad Al Banjari (Erfan \\ Karyadiputra) \\ email : erfantsy@gmail.com \\ ${ }^{2}$ Fakultas Teknologi Informasi, Universitas Islam Kalimantan Muhammad Arsyad Al Banjari (Agus \\ Setiawan) \\ email : Agusteknik08@gmail.com \\ ${ }^{3}$ Fakultas Teknologi Informasi, Universitas Islam Kalimantan Muhammad Arsyad Al Banjari (Agus \\ Setiawan) \\ email : Nadiyahijriana@gmail.com
}

\begin{abstract}
Abstrak
Pelayanan publik merupakan kegiatan pelayanan dari penyedia layanan publik dengan maksud memenuhi kebutuhan penerima layanan sesuai dengan ketentuan dan aturan yang berlaku. Kepuasan pasien merupakan hal yang sangat penting dalam menilai tingkat pelayanan obat yang diberikan kepada pasien penerima BPJS di Apotek. Tujuan penelitian ini adalah untuk memprediksi tingkat kepuasan pasien terhadap pelayanan obat kepada pasien yang ditinjau dari beberapa aspek seperti ketanggapan petugas, kecepatan pelayan obat, keramahan petugas, kenyamanan ruang tunggu, kemampuan petugas dalam menyampaikan informasi obat, pelayanan konseling, pelayanan informasi obat dan kemampuan dalam mengatasi keluhan pasien. Dari hasil pengujian algoritma melalui teknik data mining yaitu confusion matrix maka didapatkan performance akurasi sebesar 89,29\%. Adapun Penerapan particle swarm optimization (PSO) berhasil meningkatkan performance akurasi algoritma C4.5 sebesar 6,42\% sehingga menjadi $95,71 \%$ dan AUC sebesar 0,750.
\end{abstract}

Keywords : Apotek, C4.5, Data Mining, Pelayanan Obat, PSO

\section{PENDAHULUAN}

Badan Penyelenggara Jaminan Sosial (BPJS) Kesehatan adalah badan hukum yang dibentuk untuk menyelenggarakan program jaminan kesehatan tersebut dengan tujuan untuk memproteksi seluruh masyarakat dengan premi terjangkau dan dengan coverage lebih luas untuk seluruh masyarakat. [1]. Jumlah peserta Jaminan Kesehatan Nasional di Kalimantan Selatan telah mencapai jumlah 2,75 juta jiwa per Mei 2018 [2].

Salah satu tempat pelayanan kesehatan di Indonesia adalah Apotek. Apotek merupakan suatu sarana untuk melakukan pekerjaan kefarmasian dan sarana untuk penyaluran perbekalan farmasi kepada masyarakat secara luas dan merata [3]. Kepuasan pasien merupakan satu elemen yang penting dalam mengevaluasi kualitas layanan dengan mengukur respon pasien setelah menerima jasa.
Salah satu teknik yang dapat digunakan untuk mengklasifikasi dan memprediksi tingkat kepuasan pelanggan adalah dengan menggunakan teknik data mining.

Tujuan penelitian ini adalah untuk memprediksi tingkat kepuasan pasien terhadap pelayanan obat kepada pasien yang ditinjau dari beberapa aspek seperti ketanggapan petugas, kecepatan pelayan obat, keramahan petugas, kenyamanan ruang tunggu, kemampuan petugas dalam menyampaikan informasi obat, pelayanan konseling, pelayanan informasi obat dan kemampuan dalam mengatasi keluhan pasien. Hasil pengujian algoritma $\mathrm{C} 4.5$ berbasis particle swarm optimization (PSO) menggunakan confusion matrix maka akan didapatkan performance akurasi dan model pohon keputusan yang dapat digunakan sebagai bahan evaluasi. 


\section{METODE PENELITIAN a. Pengumpulan Data}

Tabel 1. Variabel Data Kepuasan Pelanggan

\begin{tabular}{|c|c|c|c|}
\hline Variabel & Keterangan & & Kategori \\
\hline \multirow{2}{*}{$\mathrm{Y}$} & \multirow{2}{*}{$\begin{array}{l}\text { Tingkat } \\
\text { Kepuasan } \\
\text { Pasien }\end{array}$} & 1 & Puas \\
\hline & & 2 & Tidak Puas \\
\hline \multirow{4}{*}{$\mathrm{X} 1$} & \multirow{4}{*}{$\begin{array}{l}\text { Ketanggapan } \\
\text { Petugas } \\
\text { Terhadap } \\
\text { Pasien }\end{array}$} & 1 & Kurang Baik \\
\hline & & 2 & Cukup Baik \\
\hline & & 3 & Baik \\
\hline & & 4 & Sangat Baik \\
\hline \multirow{4}{*}{$\mathrm{X} 2$} & \multirow{4}{*}{$\begin{array}{c}\text { Kecepatan } \\
\text { Pelayanan } \\
\text { Obat Jadi }\end{array}$} & 1 & Kurang Baik \\
\hline & & 2 & Cukup Baik \\
\hline & & 3 & Baik \\
\hline & & 4 & Sangat Baik \\
\hline \multirow{4}{*}{$\mathrm{X} 3$} & \multirow{4}{*}{$\begin{array}{l}\text { Kecepatan } \\
\text { Pelayanan } \\
\text { Obat Racik }\end{array}$} & 1 & Kurang Baik \\
\hline & & 2 & Cukup Baik \\
\hline & & 3 & Baik \\
\hline & & 4 & Sangat Baik \\
\hline \multirow{4}{*}{$\mathrm{X} 4$} & \multirow{4}{*}{$\begin{array}{c}\text { Keramahan } \\
\text { Petugas }\end{array}$} & 1 & Kurang Baik \\
\hline & & 2 & Cukup Baik \\
\hline & & 3 & Baik \\
\hline & & 4 & Sangat Baik \\
\hline \multirow{4}{*}{$\mathrm{X} 5$} & \multirow{4}{*}{$\begin{array}{l}\text { Kenyamanan } \\
\text { Ruang Tunggu }\end{array}$} & 1 & Kurang Baik \\
\hline & & 2 & Cukup Baik \\
\hline & & 3 & Baik \\
\hline & & 4 & Sangat Baik \\
\hline \multirow{4}{*}{ X6 } & \multirow{4}{*}{$\begin{array}{l}\text { Kemampuan } \\
\text { Menyampaikan } \\
\text { Informasi Obat }\end{array}$} & 1 & Kurang Baik \\
\hline & & 2 & Cukup Baik \\
\hline & & 3 & Baik \\
\hline & & 4 & Sangat Baik \\
\hline \multirow{4}{*}{$\mathrm{X} 7$} & \multirow{4}{*}{$\begin{array}{l}\text { Pelayanan } \\
\text { Konseling }\end{array}$} & 1 & Kurang Baik \\
\hline & & 2 & Cukup Baik \\
\hline & & 3 & Baik \\
\hline & & 4 & Sangat Baik \\
\hline \multirow{4}{*}{$\mathrm{X} 8$} & \multirow{4}{*}{$\begin{array}{c}\text { Pelayanan } \\
\text { Informasi Obat }\end{array}$} & 1 & Kurang Baik \\
\hline & & 2 & Cukup Baik \\
\hline & & 3 & Baik \\
\hline & & 4 & Sangat Baik \\
\hline \multirow{3}{*}{ X9 } & \multirow{3}{*}{$\begin{array}{c}\text { Kemampuan } \\
\text { Mengatasi } \\
\text { Keluhan } \\
\text { Pasien }\end{array}$} & 1 & Kurang Baik \\
\hline & & 2 & Cukup Baik \\
\hline & & 3 & Baik \\
\hline
\end{tabular}

\begin{tabular}{|c|c|c|l|}
\hline & & 4 & Sangat Baik \\
\hline \multirow{4}{*}{ X10 } & Kemampuan & 1 & Kurang Baik \\
\cline { 3 - 4 } & Menuliskan & 2 & Cukup Baik \\
\cline { 3 - 4 } & Aturan Pakai & 3 & Baik \\
\cline { 3 - 4 } & Obat & 4 & Sangat Baik \\
\cline { 3 - 4 } & &
\end{tabular}

\section{b. Pengolahan Data}

Data yang telah dikumpulkan melalui pengisian kuesioner kepada responden, selanjutnya dilakukan proses pre-processing seperti melakukan cleaning data, integrasi data dan transformasi data untuk dapat mengidentifikasi beberapa atribut-atribut yang tidak relevan sehingga kemudian dapat diproses ketahapan selanjutnya dalam teknik data mining.

\section{c. Eksperimen dan Pengujian Model}

Pada tahap ini dilakukan eksperimen dalam mengimplementasikan pengujian algoritma C4.5 menggunakan Rapidminer.

\section{d. Evaluasi dan Validasi}

Tahap selanjutnya melakukan evaluasi dan validasi menggunakan $\mathrm{x}$-validation.

\section{HASIL DAN PEMBAHASAN}

Data-data yang dikumpulkan terlebih dahulu diolah agar dapat diproses dalam data mining melalui proses pre-processing.

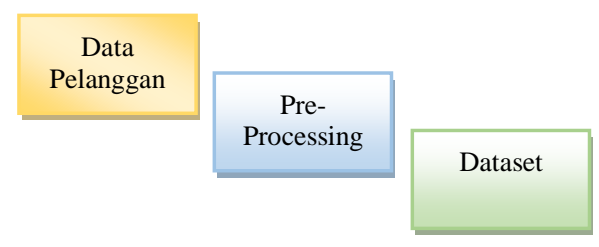

Gambar 1. Pengolahan Data

Tabel 2. Pre-Processing

\begin{tabular}{|c|c|c|c|c|c|c|c|}
\hline No & Atribut & Kelas & Nilai & No & Atribut & Kelas & Nilai \\
\hline \multirow[t]{4}{*}{1} & $\mathrm{X} 1$ & Kurang Baik & 1 & 6 & X6 & Kurang Baik & 1 \\
\hline & & Cukup Baik & 2 & & & Cukup Baik & 2 \\
\hline & & Baik & 3 & & & Baik & 3 \\
\hline & & Sangat Baik & 4 & & & Sangat Baik & 4 \\
\hline \multirow[t]{4}{*}{2} & $\mathrm{x} 2$ & Kurang Baik & 1 & 7 & $x 7$ & Kurang Baik & 1 \\
\hline & & Cukup Baik & 2 & & & Cukup Baik & 2 \\
\hline & & Baik & 3 & & & Baik & 3 \\
\hline & & Sangat Baik & 4 & & & Sangat Baik & 4 \\
\hline \multirow[t]{4}{*}{3} & $\mathrm{x} 3$ & Kurang Baik & 1 & 8 & $x 8$ & Kurang Baik & 1 \\
\hline & & Cukup Baik & 2 & & & Cukup Baik & 2 \\
\hline & & Baik & 3 & & & Baik & 3 \\
\hline & & Sangat Baik & 4 & & & Sangat Baik & 4 \\
\hline \multirow[t]{4}{*}{4} & X4 & Kurang Baik & 1 & 9 & $\times 9$ & Kurang Baik & 1 \\
\hline & & Cukup Baik & 2 & & & Cukup Baik & 2 \\
\hline & & Baik & 3 & & & Baik & 3 \\
\hline & & Sangat Baik & 4 & & & Sangat Baik & 4 \\
\hline \multirow[t]{4}{*}{5} & X5 & Kurang Baik & 1 & 10 & $\mathrm{x} 10$ & Kurang Baik & 1 \\
\hline & & Cukup Baik & 2 & & & Cukup Baik & 2 \\
\hline & & Baik & 3 & & & Baik & 3 \\
\hline & & Sangat Baik & 4 & & & Sangat Baik & 4 \\
\hline
\end{tabular}


Tabel 3. Variable Target

\begin{tabular}{|c|c|}
\hline $\begin{array}{c}\text { Variabel } \\
\text { Target }\end{array}$ & Keterangan \\
\hline Puas & $\begin{array}{c}\text { Jumlah } \\
\text { Nilai } 30-40 \\
\text { Jumlah } \\
\text { Tidak } 10-29\end{array}$ \\
\hline
\end{tabular}

Setelah data terkumpul, selanjutnya hitung Jumlah total data, kemudian hitung jumlah total data dengan variabel puas dan tidak puas seperti tabel berikut.

Tabel 4. Dataset

\begin{tabular}{|c|cc|c|c|}
\hline & $\begin{array}{c}\text { Jumlah } \\
\text { Atribut }\end{array}$ & $\begin{array}{c}\text { Jumlah } \\
\text { Data }\end{array}$ & Puas & $\begin{array}{c}\text { Tidak } \\
\text { Puas }\end{array}$ \\
\hline Total & 10 & 67 & 51 & 16 \\
\hline
\end{tabular}

Kemudian menghitung jumlah entrophy dari tiap-tiap jumlah dan atribut data dengan persamaan berikut:

Entropy $=\sum_{i=1}^{N}-P i \log _{2} P i$

Dimana :
S : Himpunan kasus
A : Fitur
$\mathrm{N}$ : Jumlah partisi $\mathrm{S}$
Pi : Proporsi dari Si terhadap S

Sementara itu, untuk memilih atribut akar, didasarkan pada nilai gain tertinggi dari atribut-atribut yang ada. Untuk menghitung gain digunakan persamaan berikut:

$$
\operatorname{GAIN}(S, A)=\operatorname{Entropy}(S)-\sum_{i=1}^{N}-\frac{|S i| \times \operatorname{Entropy}(S i)}{|S|}
$$

Dimana :

$\mathrm{S}$ : Himpunan kasus

A : atribut

$\mathrm{N}$ : jumlah partisi atribut $\mathrm{A}$

$|\mathrm{Si}|$ : Jumlah kasus pada partisi ke-i

$|S|$ : Jumlah kasus dalam $S$
Tabel 5. Perhitungan Entrophy \& Gain

\begin{tabular}{|c|c|c|c|c|c|c|}
\hline \multirow{2}{*}{ TOTAL } & & \multirow{2}{*}{\begin{tabular}{c|} 
JUMLAH \\
67 \\
\end{tabular}} & \multirow{2}{*}{\begin{tabular}{|c|} 
PUAS \\
51 \\
\end{tabular}} & \multirow{2}{*}{$\begin{array}{c}\text { TIDAK PUAS } \\
16\end{array}$} & \multirow{2}{*}{$\begin{array}{l}\text { ENTROPY } \\
0,793049005\end{array}$} & \multirow[t]{2}{*}{ GAIN } \\
\hline & & & & & & \\
\hline & & & & & & \\
\hline & & & & & & \\
\hline & & & & & & \\
\hline & & & & & & \\
\hline \multirow[t]{4}{*}{$\mathrm{X} 1$} & & & & & & 0,1760741 \\
\hline & CUKUP BAIK & 3 & 0 & 3 & 0 & \\
\hline & BAIK & 50 & 37 & 13 & 0,826746372 & \\
\hline & SANGAT BAIK & 14 & 14 & 0 & 0 & \\
\hline \multirow[t]{4}{*}{$\mathrm{X} 2$} & & & & & & 0,118943028 \\
\hline & CUKUP BAIK & 2 & 0 & 2 & 0 & \\
\hline & BAIK & 46 & 33 & 13 & 0,858981037 & \\
\hline & SANGAT BAIK & 19 & 18 & 1 & 0,297472249 & \\
\hline \multirow[t]{4}{*}{$\mathrm{X} 3$} & & & & & & 0,15344301 \\
\hline & CUKUP BAIK & 16 & 7 & 9 & 0,988699408 & \\
\hline & BAIK & 41 & 34 & 7 & 0,659375881 & \\
\hline & SANGAT BAIK & 10 & 10 & 0 & 0 & \\
\hline \multirow[t]{4}{*}{$\mathrm{X} 4$} & & & & & & 0,258518594 \\
\hline & CUKUP BAIK & 3 & 0 & 3 & 0 & \\
\hline & BAIK & 39 & 26 & 13 & 0,918295834 & \\
\hline & SANGAT BAIK & 25 & 25 & 0 & 0 & \\
\hline \multirow[t]{4}{*}{$\mathrm{X} 5$} & & & & & & 0,147661706 \\
\hline & CUKUP BAIK & 2 & 0 & 2 & 0 & \\
\hline & BAIK & 51 & 37 & 14 & 0,847861745 & \\
\hline & SANGAT BAIK & 14 & 14 & 0 & 0 & \\
\hline \multirow[t]{4}{*}{$\mathrm{X} 6$} & & & & & & 0,127639585 \\
\hline & CUKUP BAIK & 4 & 1 & 3 & 0,811278124 & \\
\hline & BAIK & 50 & 37 & 13 & 0,826746372 & \\
\hline & SANGAT BAIK & 13 & 13 & 0 & 0 & \\
\hline \multirow[t]{4}{*}{$\mathrm{X} 7$} & & & & & & 0,225759823 \\
\hline & CUKUP BAIK & 5 & 0 & 5 & 0 & \\
\hline & BAIK & 50 & 39 & 11 & 0,760167503 & \\
\hline & SANGAT BAIK & 12 & 12 & 0 & 0 & \\
\hline \multirow[t]{4}{*}{$\mathrm{X} 8$} & & & & & & 0,343829734 \\
\hline & CUKUP BAIK & 8 & 0 & 8 & 0 & \\
\hline & BAIK & 44 & 36 & 8 & 0,684038436 & \\
\hline & SANGAT BAIK & 15 & 15 & 0 & 0 & \\
\hline \multirow[t]{4}{*}{$\mathrm{X9}$} & & & & & & 0,238522647 \\
\hline & CUKUP BAIK & 8 & 1 & 7 & 0,543564443 & \\
\hline & BAIK & 46 & 37 & 9 & 0,713146749 & \\
\hline & SANGAT BAIK & 13 & 13 & 0 & 0 & \\
\hline \multirow[t]{4}{*}{$\mathrm{X} 10$} & & & & & & 0,234843628 \\
\hline & CUKUP BAIK & 7 & 1 & 6 & 0,591672779 & \\
\hline & BAIK & 42 & 32 & 10 & 0,791858353 & \\
\hline & SANGAT BAIK & 18 & 18 & 0 & 0 & \\
\hline
\end{tabular}

Berdasarkan Tabel 5, dapat diketahui bahwa atribut dengan gain tertinggi adalah X8 (pelayanan Informasi Obat), yaitu 0.343829734. Dengan demikian X8 dapat dijadikan node akar.

Selanjutnya melakukan implementasi pengujian algoritma C4.5 menggunakan Rapidminer 5.3.

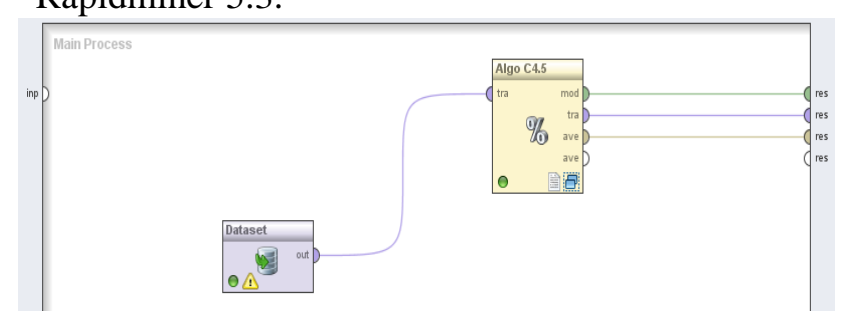

Gambar 2. Implementasi C4.5 
Selanjutnya melakukan evaluasi dan validasi melalui pengujian confusion matrix dan kurva ROC sehingga diketahui akurasi dan modelnya.

\begin{tabular}{|llll|}
\hline \multicolumn{2}{|l|}{ accuracy: $89.29 \%+1.10 .28 \%$ (mikro: 89.55\%) } & & \\
\hline \hline & true Puas & true Tidak Puas & class precision \\
\hline pred. Puas & 46 & 2 & $95.33 \%$ \\
\hline pred. Tidak Puas & 5 & 14 & $73.68 \%$ \\
\hline class recall & $90.20 \%$ & $87.50 \%$ & \\
\hline
\end{tabular}

Gambar 3. Hasil Akurasi C.45

Dari hasil pengujian 10-fold crossvalidation, didapatkan akurasi sebesar $89,29 \%$ dengan nilai AUC sebesar 0,610.

Selanjutnya untuk memperbaiki tingkat performance algoritma C.45 maka dilakukan optimasi menggunakan particle swarm optimization (PSO).

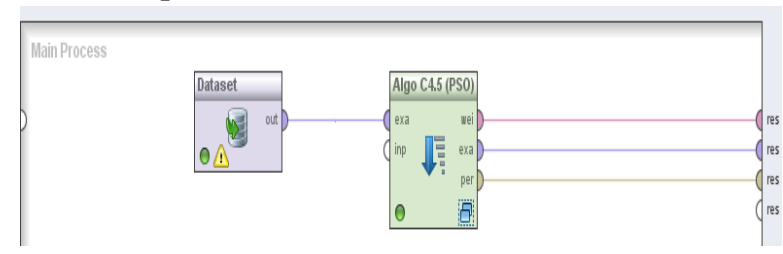

Gambar 4. Optimasi (PSO)

Dari hasil penerapan optimasi menggunakan particle swarm optimization berhasil meningkatkan performance algoritma C.45 dengan peningkatan nilai akurasi menjadi 95,71\% dengan nilai AUC sebesar 0,750.

\begin{tabular}{|c|c|c|c|}
\hline \multicolumn{4}{|c|}{ accuracy: $92.90 \%$ +1.5.54\% (mikro: $92.86 \%$ ) } \\
\hline & true Baik & true Kurang Baik & class precision \\
\hline pred. Baik & 114 & 9 & $92.68 \%$ \\
\hline pred. Kurang Baik & 1 & 16 & $94.12 \%$ \\
\hline class recall & $99.13 \%$ & $64.00 \%$ & \\
\hline
\end{tabular}

Gambar 5. Hasil Akurasi C4.5 Berbasis PSO

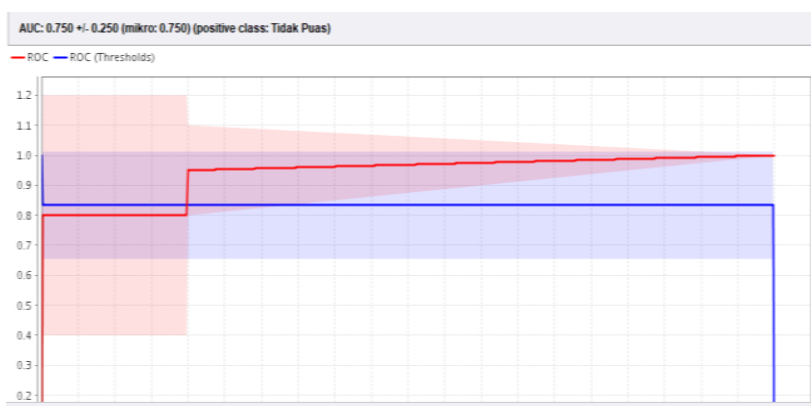

Gambar 6. Kurva ROC
Adapun hasil komparasi performance algoritma C.45 dapat terlihat pada tabel berikut :

\begin{tabular}{|l|l|l|}
\hline \multicolumn{1}{|c|}{ Algoritma } & Akurasi & AUC \\
\hline C4.5 & $89,29 \%$ & 0,610 \\
\hline C4.5 + PSO & $95,71 \%$ & 0,750 \\
\hline
\end{tabular}

Selanjutnya untuk melihat keakuratan klasifikasi maka sampel data training dibandingkan dengan hasil klasifikasi algoritma $\mathrm{C} 4.5$

\begin{tabular}{|c|c|c|c|c|c|c|c|c|c|c|c|c|}
\hline \multicolumn{8}{|c|}{ 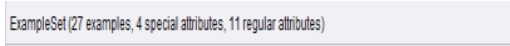 } & \multicolumn{5}{|c|}{ View Filter (27127): all } \\
\hline Rowno. & TNGKATK. & confidencel. & L. confidencel- & predidition(T_- & - UIMUR & $\mathrm{P1}$ & P2 & P3 & P4 & P5 & P6 & P7 \\
\hline 1 & Puas & 1 & 0 & Puas & 20-35Tahu $\mathrm{B}$ & & Baik & Sangat Baik B & & Baik & Sangat Baik $\$$ & Sangat Baik| \\
\hline 2 & Puas & 1 & 0 & Puas & 20-35Tahu $B$ & & Baik & Balk 8 & Baik & Baik & Balk B & Baik \\
\hline 3 & TidakPlass & 0 & 1 & TidakPluas & 20-35Tahu $\mathrm{B}$ & & Baik & Cukup Baik 0 & Cukup Baik & Cukup Baik & Cunpp Baik 0 & Cunvp Baik \\
\hline 4 & Puas & 1 & 0 & Puas & 20-35T Thu $\mathrm{B}$ & & Baik & Baik & Baik & Sangat Baik & Baik B & Baik \\
\hline 5 & Tidak Puas & 0 & 1 & Tilake Puas & $20-35$ Tahu $B$ & & Sangat Baik & Cukvp Baik $B$ & Baik & Baik & Baik & Baik \\
\hline 6 & Puas & 1 & 0 & Puas & 20-35 Tahu $\mathrm{B}$ & & Sannat Baik & (Sangat Baik S & Sangat Baik & Baik & Baik & Baik \\
\hline 7 & Puas & 1 & 0 & Puas & $<20$ Tahun 8 & & Baik & Baik B & Baik & Baik & Baik & Baik \\
\hline 8 & Puas & 1 & 0 & Puas & $>35$ Tahun 8 & & Baik & Baik & Baik & Baik & Baik & Baik \\
\hline 9 & Puas & 1 & 0 & Puas & $>35$ Tahun 8 & & Baik & Baik & Baik & Baik & Baik & Baik \\
\hline 10 & Tidak Puas & 1 & 0 & Puas & >35T Tahun 8 & & Baik & Baik & Baik & Baik & Baik & Baik \\
\hline 11 & Tidak Puas & $?$ & $?$ & Puas & 20-35 Tahu $B$ & & Baik & Cukvp Baik : & Baik & Baik & Baik & Baik \\
\hline 12 & Puas & 1 & 0 & Puas & 20-35 Tahu $\mathrm{B}$ & & Baik & Baik B & Baik & Baik & Sangat Baik B & Baik \\
\hline 13 & Puas & 1 & 0 & Puas & 20-35Tahu $\mathrm{B}$ & & Baik & Baik & Baik & Baik & Baik B & Baik \\
\hline 14 & TidakPluas & 0 & 1 & TidakP Puas & 20-35T Thu 8 & & Baik & Cukpp Baik B & Baik & Baik & Baik & Baik \\
\hline 15 & Tidak Puas & 0 & 1 & Tidak Puas & $>35$ Tahun 8 & & Baik & Baik & Baik & Baik & Baik & Culupp Baik \\
\hline 16 & Puas & 1 & 0 & Pvas & 20-35Tathu $B$ & & Sangat Baik & Baik & Sangat Bak & Sangat Baik & Baik & Balik \\
\hline 17 & Puas & 1 & 0 & Puas & $>35$ Tahun 8 & & Baik & Baik & Baik & Baik & Baik & Baik \\
\hline 18 & Puas & 1 & 0 & Puas & $>35$ Tahun & & Baik & Baik & Baik & Baik & Baik & Baik \\
\hline 19 & Puas & 1 & 0 & Puas & 20-35 Tahu S & Sangat Baik & K SangatBaik & Baik & Sangat Baik & Baik & Sangat Baik B & Baik \\
\hline 20 & Puas & 1 & 0 & Puas & $>35$ Tahun 8 & gaik & Baik & Baik & Baik & Baik & Baik & Baik \\
\hline 21 & Tidak Puas & 0 & 1 & Tidak Puas & $<20$ Tahun $\mathrm{B}$ & & Baik & Baik & Baik & Baik & Baik & Baik \\
\hline 22 & TriakPluas & 0 & 1 & Tidak Puas & 20-35 Thu & Cunup Baik & k. Cukup Baik & Cukpop Baik & Cunjp Baik & K Culup Baik & Culup Baik & Culup Baik \\
\hline 23 & Puas & 1 & 0 & Puas & $>35$ Tahun & & Baik & Baik & Baik & Baik & Baik & Baik \\
\hline 24 & Puas & 1 & 0 & Puas & 20-35T Tahu & & Baik & Baik & Baik & Baik & Baik & Baik \\
\hline 25 & TrabrPuas & $?$ & $?$ & Puas & 20-35Tahu & & Baik & Cunup Baik & Baik & Baik & Baik & Baik \\
\hline 26 & TriakPluas & 0 & 1 & Tidak Puas & $>35$ Tahun & Cunup Baik & k. Cukup Baik & Cukpp Baik & Cunjp Baik & K Baik & Baik & Baik \\
\hline 27 & Puas & 1 & 0 & Puas & $>355$ Tahun & Baik & Baik & Baik & Baik & Baik & Baik & Sangat Baik \\
\hline
\end{tabular}

Dari hasil perbandingan sampel 27 data training yang diuji dengan hasil klasifikasi maka sebagian besar berhasil memprediksi dengan benar dan hanya didapatkan 2 data sampel hasil klasifikasi yang tidak sesuai dengan data training. 
Adapun model pohon keputusan yang terbentuk seperti gambar dibawah ini :

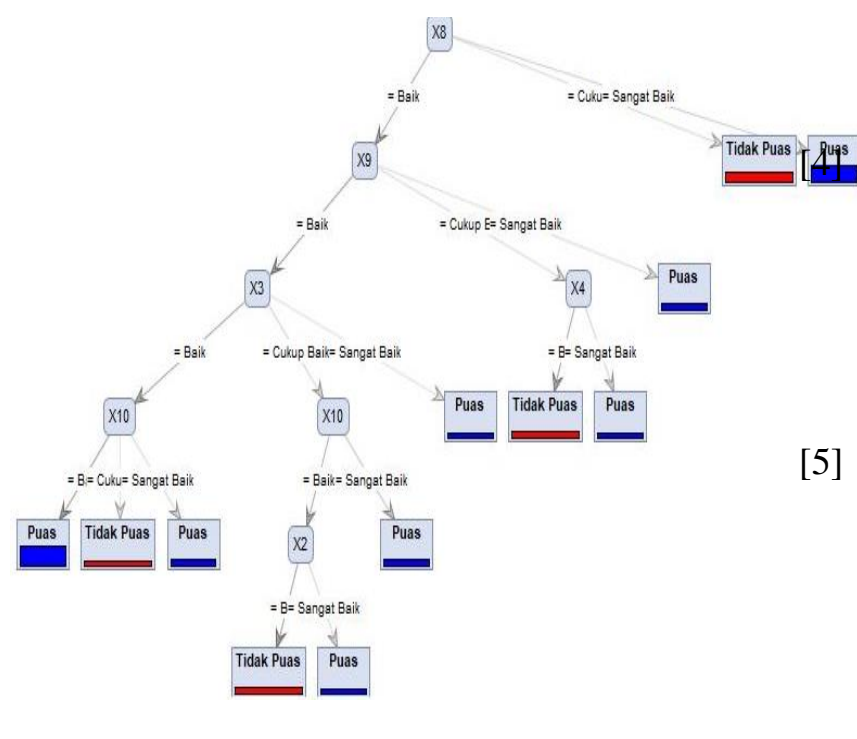

Gambar 7. Model Pohon Keputusan

\section{KESIMPULAN}

Dari hasil penelitian yang dilakukan dari tahap awal pengujian hingga akhir pengujian, maka dapat disimpulkan bahwa penerapan teknik optimasi menggunakan particle swarm optimization (PSO) berhasil meningkatkan performance algoritma C.45 dari akurasi $89,29 \%$ menjadi $95,71 \%$ sehingga terjadi peningkatan nilai akurasi sebesar $6,42 \%$. C4.5 berbasis PSO juga meningkatkan tingkat klasifikasi dari poor classification $(0,610)$ menjadi fair classification $(0,750)$.

\section{REFERENSI}

[1] A. Abidin, "Pengaruh Kualitas Pelayanan Bpjs Kesehatan Terhadap Kepuasan Pasien Di Puskesmas Cempae Kota Parepare," Vol. 12, No. 2, Pp. 70-75, 2016.

[2] M. Fakhriza, "Perluasan Cakupan Peserta \& Peningkatan Kolektabilitas Iuran Jaminan Sosial Bidang Kesehatan," 2018.
[3] Helni, “Tingkat Kepuasan Pasien Terhadap Pelayanan Apotek Di Kota Jambi," Fak. Kedokt. Dan Ilmu Kesehat. Univ. Jambi, Vol. 17, No. 51, Pp. 01-08, 2015.

Rismayanti, "Decision Tree Penentuan Masa Studi Mahasiswa Prodi Teknik Informatika ( Studi Kasus: Fakultas Teknik Dan Komputer Universitas Harapan Medan )," J. Sist. Inf., Vol. 5341, No. April, Pp. 16-24, 2018.

N. Azwanti, "Analisa Algoritma C4.5 Untuk Memprediksi Penjualan Motor Pada Pt. Capella Dinamik Nusantara Cabang Muka Kuning," Inform. Mulawarman J. Ilm. Ilmu Komput., Vol. 13, No. 1, P. 33, 2018.

[6] S. Budi, "Text Mining Untuk Analisis Sentimen Review Film Menggunakan Algoritma K-Means," Techno.Com, Vol. 16, No. 1, Pp. 1-8, 2017.

[7] Dian Puteri Ramadhani, "Analisis Model Prediksi Elektabilitas Calon Legislatif Menggunakan Data Pemilu Sebagai Data Training,” 2016. [Online]. Available: Https://Dianrdntelkomuniversity.Word press.Com/2016/10/23/Analisis-ModelPrediksi-Elektabilitas-Calon-LegislatifMenggunakan-Data-Pemilu-SebagaiData-Training/.

[8] F. Gorunescu, Data Mining: Concepts, Models And Techniques. SpringerVerlag Berlin Heidelberg, Intelligent Systems References Library, 2011.

[9] Priati, "Kajian Perbandingan Teknik Klasifikasi Algoritma C4.5, Naïve Bayes Dan Cart Untuk Prediksi Kelulusan Mahasiswa (Studi Kasus: Stmik Rosma Karawang)," Media Inform., Vol. 15, No. 2, Pp. 1-17, 2016. 